\title{
Internal Entrainment Effects on High Intensity Distributed Combustion Using Non-Intrusive Diagnostics
}

\author{
Ahmed E.E. Khalil and Ashwani K. Gupta*
}

Department of Mechanical Engineering, University of Maryland, College Park, MD 20742, USA

Abstract

High intensity colorless distributed combustion (CDC) provides high efficiency combustion with stable operation and ultra-low emissions. The role of internal entrainmentof hot reactive gases requires further investigationin order to obtain minimum requirements for distributed combustion. In this paper, the impact of internal entrainment of reactivegases on the flame behavior and structure is investigated with focus on fostering distributed combustion.A mixture of nitrogen and carbon dioxide was introduced to the air stream prior to mixing with the fuel to simulate the recirculated product gases from within the combustor. Increase dilution with nitrogen or carbon dioxide increased the reaction zone volume to result in uniform distribution of $\mathrm{CH}^{*}$ and $\mathrm{OH}^{*}$ chemiluminescence signal and uniform equivalence ratio (measured optically). These conditions replaced the normally present blue flame with a uniform almost invisible faint bluish flame. The increased entrainment also decreased NO chemiluminescence significantly for the same amounts of fuel burned. The chemiluminescence data suggested that lowering oxygen concentration from $21 \%$ to $15 \%$ resulted in improved distributed combustion conditions with the reaction volume occupying most of the combustor. These conditionsprovide the minimum entrainment requirement and reduction of oxygen concentration for achieving distributed combustion. Results obtained at different equivalence ratios and entrained gas temperaturesshowed similar behavior at oxygen concentration of $15 \%$. The reaction distribution was further enhanced at lower oxygen concentration $(\sim 11 \%)$ with further reduction in pollutants emissions.

Keywords:High intensity distributed combustion,Gas turbine combustion, Local equivalence ratio, Reactive gas entrainment, Ultra low $\mathrm{NO}_{\mathrm{x}}$.

\section{Introduction}

Increasing energy needs, with rising concerns about global warming and climate change, have

35 motivated researchers to develop new methods of energy conversion using available energy sources with minimal impact on the environment. From these sources, natural gas and shale gas

"Distinguished University Professor, Corresponding author:Tel.: +1 301405 5276; Fax: +1 301 3149477.

E-mail address: akgupta@umd.edu(A.K.Gupta). 
provide themselves as low carbon energy sources that can be converted to usable energy through combustion with minimal environmental impact (as compared to other fossil fuel). The potential for these gases for electricity and power generation have been fostered by their increased 40 availability as a local energy source. The combustion systems developed for natural gas need to comply with the stringent emissions regulation to form a pivotal part of the quest for environmentally friendly energy systems. To ensure environmentally friendly performance, these combustion systems shall achieve near zero emission of pollutants (such as, $\mathrm{NO}_{\mathrm{x}}, \mathrm{CO}$, unburned hydrocarbons and soot) while minimizing $\mathrm{CO}_{2}$ emissions. To this end, colorless distributed

45 combustion (CDC) has been shown to provide the benefits of reducing the emissions of NO and $\mathrm{CO}$, and improved pattern factor with enhanced thermal field uniformity in the entire combustor [1-3]. Stable combustion with reduced noise and no flame fluctuations have also been shown for CDC conditions along with fuel flexibility [4] and enhanced thermal field uniformity [5]. The flames in distributed combustion do not show any visible flame signatures so that the flame so

50 formed is termed colorless due to negligible visible emission as compared to conventional flames.

The performance gains from CDC have been demonstrated using different geometrical arrangement for the combustor flowfield, air injection, and fuel injection [6-9]. These geometries and injection scenarios were examined with focus on enhancing the entrainment of hot reactive

55 gaseousspecies from within the combustor and their subsequent mixing with the freshly introduced air and fuel. This entrainment and the subsequent adequate mixing prior to ignition are critical components to achieve distributed reactions. Distributed reactions are characterized by a lower reaction rate over the entire volume of the combustor, as opposed to the concentrated flame front characterized by high reaction rates with local hot spots, to result in the same fuel 
60 consumption with lower temperature rise in the combustor. This lowreaction rate is achieved through lowering the oxygen concentration in the reactants, and maintained by the increased temperature of the reactants (both achieved simultaneously through the entrainment of hot reactive gases). The distributed combustion regime not only avoids the formation of thin reaction zone but also the hot-spots in the flame that help mitigate thermal $\mathrm{NO}_{\mathrm{x}}$ formation and emission

65 fromthe Zeldovichthermal mechanism[10, 11].

For all the aforementioned investigations, increased entrainment of hot reactive gases from within the combustor decreased emissions and enhanced thermal field uniformity in the combustion chamber;however, critical questions concerning the minimum required amount of entrainmentremains unaddressed. Increasing the entrainment of hot reactive gases and their

70 mixing with the fresh reactants lowers the oxygen concentration in the overall mixture and increases the mixture temperature, but no information is available on the required oxygen concentration to achieve distributed reactions. Previous results have provided the basic requirements on conditions (such as, oxygen concentration and temperature) to achieve distributed reactions in furnaces $[11,12]$, which are characterized by lower thermal intensity and

75 near stoichiometric combustion. It was concludedthat oxygen concentration of about $8 \%$ or lower results in no color (colorless) to the flame. Other researchers have shown that the reaction is more distributed at $4 \%$ oxygen concentration as compared to $21 \%$ oxygen in air. This was demonstrated with and without air preheats prior to combustion [13]. However, these two studies focused on low intensity combustion characteristic of furnaces rather than the present efforts on 80 high intensity gas turbines.

For gas turbine combustors, $40 \%$ reduction in $\mathrm{NO}_{\mathrm{x}}$ has been demonstrated with $35 \%$ exhaust gas recirculation (EGR), leading to an oxygen concentration of 17\% [14]. Other researchers have 
reached similar performance gains with up to $30 \%$ EGR [15]; however, there is limited information on reaction behavior at lower oxygen concentrations as stable operation was not

85 maintained with further increase in EGR amounts [14, 15].

The impact of entrainment on pollutants emission and reaction distribution has been studied with focus on achieving distributed reaction [16]. Different amounts of $\mathrm{N}_{2}-\mathrm{CO}_{2}$ mixture simulating product gases were added to the fresh mixture at different temperatures for diluting the fresh mixture and lowering its oxygen concentration to simulate recirculation of hot product

90 gases from within the combustor to achieve distributed combustion conditions. It was concluded that oxygen reduction of $3 \%$ (down to $18 \%$ ) resulted in about $60 \%$ reduction in NO emission, and $75 \%$ reduction of $\mathrm{NO}$ emission with further reduction of oxygen concentration by $2 \%$ (down to $16 \% \mathrm{O}_{2}$ in mixture), outlining the significant impact of oxygen concentration on the behavior of the mixture and the resulting emissions [16]. This investigation focused on only the final 95 outcome in terms of pollutants emission. In this paper, the flame characteristics and shape are examined for different amounts of gas entrainmentin an effort to understand the difference in flame behavior and reaction progression under distributed reactioncondition as compared to normal flames. A swirl burner was used in this investigation with focus on detecting different flame light emissions and chemiluminescence.

\section{Approach}

To evaluate the flame characteristics with different amounts of entrainment, light emission spectroscopy was used as the diagnostic tool to examine the presence of different radicals. Excited radicals emission has been extensively used to determine the extent of reaction 
105 distribution under different conditions. The use of selected radicals provided insights on the local equivalence ratio.

\subsection{Equivalence Ratio}

The first characteristic quantified here is the equivalence ratio and its variation with the reaction distribution. Since the chemiluminescence intensities relate tothe species produced

110 during the reactionprocess, the intensity of light produced (or the signal captured) is related to therate of production/depletion of each species. These ratesvary with reaction progression and is a function ofequivalence ratio. Consequently, one can deduce theequivalence ratio from the chemiluminescenceintensities. Numerous researchers have shown that the ratios of chemiluminescencefrom different radicals, such as $\mathrm{OH}^{*} / \mathrm{CH}^{*}$ and $\mathrm{C}_{2} * / \mathrm{OH}^{*}$, vary with

115 equivalence ratio in simpleflames [17-24] including liquid fueled flames [25]. In all this investigations, a similar trend was shown where the $\mathrm{OH}^{*} / \mathrm{CH} *$ ratio was shown to increase significantly for lean equivalence ratios.

Several researchers have focused their efforts on developing this method for equivalence ratio measurements in a swirl combustor relating to gas turbine applications with focus on lean

120 combustion. Muruganandamet al.[26] have shown that the $\mathrm{CH}^{*} / \mathrm{OH}^{*}$ signal ratio for turbulent jet flame, swirl dump combustor, and gas turbine simulator exhibit the same trend and similar value for equivalence ratios between 0.65 and 0.95 . Other researches have reached similar conclusions on the trend of $\mathrm{CH}^{*} / \mathrm{OH}^{*}$ ratio (or $\mathrm{OH}^{*} / \mathrm{CH}^{*}$ ) in swirl burners [27-29].Muruganandamet al. [28] have shown that the $\mathrm{CH}^{*} / \mathrm{OH}^{*}$ ratio remains almost the same for Reynolds numbers in the

125 range of 11700 and 23300. They also showed that their swirl combustor data agrees favorably well with high pressure premixed laminar flame results [18]. Guyot and Lacarelle[29] measured the $\mathrm{CH}^{*} / \mathrm{OH}^{*}$ ratio for Alstom EV-10 burner. They concluded that this ratio depends 
exponentially on the equivalence ratio and is independentof the air mass flow. They noted that the contribution of broadband $\mathrm{CO}_{2}^{*}$ chemiluminescencein the wavelength range of $\mathrm{CH}^{*}$ 130 chemiluminescence must be accounted for. Similar concerns were raised concerning $\mathrm{CO}_{2}{ }^{*}$ chemiluminescence. Muruganandamet al.[28] noted that the trend can be different if no background correction is performed to account for $\mathrm{CO}_{2}$ chemiluminescence. An example of this is the work of Docquieret al. [30],where the data trend is different than that recorded with background correction $[28,18]$, outlining the importance of $\mathrm{CH}^{*}$ signal correction to account for

$135 \mathrm{CO}_{2}$ chemiluminescence and any other background noise.

\subsection{NO* Chemiluminescence}

Nitric oxides formation is one of the major issues in gas turbines combustion with ongoing focus on how to minimize or eliminate these emissions. Thermal field uniformity and low temperature rise remains the main issue to tackle thermal $\mathrm{NO}_{\mathrm{x}}$ formation through the Zeldovich

$140 \mathrm{NO}_{\mathrm{x}}$ formation mechanism. In-situ NO detection have been performed using planar laser induced fluorescence (NO-PLIF)[31-34]. For these experiments, the light emission from NO was captured in the range of $230-280 \mathrm{~nm}$. NO can also be thermally and chemically excited in that range of wavelengths, emitting light through the $\mathrm{A}^{2} \Sigma=\mathrm{X}^{2} \Pi$ transition[35]. Simulations performed for NO light emission showed strong signal in this range [36]. Consequently, NO presence can

145 be detected through $\mathrm{NO}^{*}$ chemiluminescence using an appropriate UV filter. A review of molecule spectra indicated that multiple molecules can emit light in the range of 230-270nm, such as $\mathrm{PO}, \mathrm{CF}, \mathrm{SiO}, \mathrm{NO}, \mathrm{CS}, \mathrm{BiO}, \mathrm{SO}$. However, $\mathrm{NO}$ is the only molecule that can be present in our experiment, indicating that any signal captured in this range will be a result of NO emission [35].This captured signal will indicate the presence of NO qualitatively and hence can 150 be used for comparative purposes between different cases examined in this study. It is postulated 
that high chemiluminescence signal indicates the presence of large amount of excited NO in an area of high temperature, and a low signal indicates a rather low population of excited NO in a low temperature region.Intermediate signals can be a combination of high NO population in low temperature region or low NO population in high temperature region. In any case, a decrease in

155 the NO signal shall indicate a combination of reduction of NO population and a lower temperature, making this signal (NO chemiluminescence) an additional useful tool to describe reaction distribution.

\section{Experimental Facility}

160 The experiments were performed usinga swirl burner fueled with methane. Previous experiments have outlined the pollutants emission and reaction distribution under different oxygen concentration through entrainment of different amounts of $\mathrm{N}_{2}-\mathrm{CO}_{2}$ mixture [16]. The details and performance of this swirl burner havebeen discussed with focus onpollutants emission and velocity profiles using methane and hydrogen enriched methane fuels [37-38].

165 Air and nitrogen flow rates were controlled by laminar flow controllers having an accuracy of $\pm 0.8 \%$ of reading $\pm 0.2 \%$ of full scale leading to an overall accuracy of about $1.5 \%$ of the reading. Methane and carbon dioxide flow rates were controlled through gravimetric flow controllershaving an accuracy of $1.5 \%$ of full scale.

To quantify flame characteristics and visual emissions, an ICCD camera coupled to a narrow

170 band filter was used for the appropriate species to be recorded. For $\mathrm{OH}^{*}$, a UV interference filter centered at $307 \mathrm{~nm}$ with a FWHM of $\pm 10 \mathrm{~nm}$ was used. This filter had a quantum efficiency of about $17 \%$. For $\mathrm{CH}^{*}$, a visible filter centered at 430nm with a FWHM of $\pm 10 \mathrm{~nm}$ was used with an efficiency of $48 \%$. To account for background noise and $\mathrm{CO}_{2} *$ chemiluminescence, two filters 
at $410 \mathrm{~nm}$ and 450 with a FWHM of $\pm 10 \mathrm{~nm}$ were used. These two filters had an efficiency of 175 about $55 \%$. The signal from both filters was averaged to obtain the noise at $430 \mathrm{~nm}$. The $\mathrm{CH}^{*}$ signal was corrected as follows

$$
\mathrm{CH}_{\text {corrected }}=\mathrm{CH}_{\text {signal }}-\left[\left(\mathrm{Signal}_{410}+\mathrm{Signal}_{450}\right) / 2\right]
$$

where, $\mathrm{CH}_{\text {corrected }}$ is the background corrected $\mathrm{CH}$ chemiluminescence image, $\mathrm{CH}_{\text {signal }}$ is the raw signal captured at $430 \mathrm{~nm}$, Signal $_{410}$ is the efficiency corrected signal captured at $410 \mathrm{~nm}$ and

180 Signal $_{450}$ is the efficiency corrected signal captured at $450 \mathrm{~nm}$. To account for the difference in efficiencies, a standard mercury calibration lamp was used to verify these efficiencies and obtain conversion factors for different wavelengths. These conversions accounted for different filter efficiencies and for the sensor and intensifier quantum efficiencies at different wavelengths. These conversion factors were used to obtain a true $\mathrm{CH}^{*} / \mathrm{OH}^{*}$ ratio without any of the filter and 185 camera efficiencies affecting this ratio. The conversion factors are as follow:

$$
\mathrm{OH}_{\text {corrected }}=\mathrm{OH}_{\text {signal }} * 1.885
$$

Signal $_{410}=$ RawSignal $_{410} / 2.1733$

$$
\text { Signal }_{450}=\text { RawSignal }_{450} / 2.1733
$$

where, $\mathrm{OH}_{\text {corrected }}$ is the efficiency corrected $\mathrm{OH}$ chemiluminescence image, $\mathrm{OH}_{\text {signal }}$ is the raw 190 signal captured at $307 \mathrm{~nm}$, $\operatorname{Signal}_{410}\left(\right.$ or $\left.\operatorname{Signal}_{450}\right)$ is the efficiency corrected signal captured at 410nm (or 450nm) and RawSignal $410($ or RawSignal 450 ) is the raw signal captured at 410nm (or 450nm).

For NO, a UV interference filter centered at $248 \mathrm{~nm}$ with a FWHM of $\pm 15 \mathrm{~nm}$ was used. This filter had a quantum efficiency similar to that of the $\mathrm{OH}^{*}$ filter $(307 \mathrm{~nm}$ with a FWHM of $195 \pm 10 \mathrm{~nm}$ ); consequently they can be directly compared as the camera had the same detection efficiency for this wavelength range. 
The signals were recorded using the five filters discussed $(248 \mathrm{~nm}, 307 \mathrm{~nm}, 410 \mathrm{~nm}, 430 \mathrm{~nm}$, and $450 \mathrm{~nm}$ ) one after the other, and the images were processed to account for any shift to the camera that might happen during filter change. The gain was kept constant for all the

200 experiments with an exposure time of $100 \mathrm{~ms}$. For each experimental condition and filter, 10 shots were averaged together to produce the raw signal that was then processed to account for noise and quantum efficiencies as described earlier.

The experimental rig is shown in Fig. 1, along with the flame at two different conditions of standard air combustion wherein the swirl structure is dominant, and reduced oxygen 205 concentration combustion showing near distributed combustion with less visible emission. Thermocouples were fitted along the reactor walls to confirm the existence of reaction zone at low oxygen concentration as the flame was invisible with almost no combustion noise.

\section{Experimental Investigations}

210 The experimental investigations reportedherein were aimed at examiningthe reaction behavior and distribution with different amount of dilution (different oxygen concentration in the mixture) and compare the behavior forNO and $\mathrm{CO}$ emission. Oxygen concentration was varied through supplying different amounts of $\mathrm{N}_{2}-\mathrm{CO}_{2}$ dilution mixture (90\%-10\% by volume). First, experiments were performed under two equivalence ratio (0.9 and 0.7). Afterwards, the

215 experiment was repeated using preheated diluents (600K) for simulating recirculated gases from within the combustor.

Table 1 summarizes the conditions reported here along with the variables manipulated for each case. For each heat load, the fuel flow rate was kept constant while the air flow rate was changed to change the equivalence ratio. For every equivalence ratio, air and fuel flow rates were 
220 kept constant while the amount of $\mathrm{N}_{2}-\mathrm{CO}_{2}$ mixture was increased to lower the oxygen concentration in the mixture prior to ignition.

\section{Results and Discussion}

\subsection{Experiments with Diluents at $300 \mathrm{~K}$}

225 Experiments conducted using $\mathrm{N}_{2}-\mathrm{CO}_{2}$ mixtures at $300 \mathrm{~K}$ were at a heat load of $3.25 \mathrm{kWusing}$ constant fuel flow rate. Air flow rate was changed to result in different equivalence ratios (0.9 and 0.7). Changing the relative amounts of $\mathrm{N}_{2}-\mathrm{CO}_{2}$ in the mixture providedchange in oxygen concentration change, down to $13.8 \%$. Figure 2 shows flame images for the case of no dilution (normal $21 \%$ oxygen concentration air) and different dilution amounts (down to $13.8 \% \mathrm{O}_{2}$ ) at an

230 equivalence ratio of 0.9 . As the diluents amount was increased, the flame became more distributed and of uniform shape, covering a larger portion of the combustor with a decrease in visible flame signature. This reduction in visible flame signature was also accompanied by reduction in combustion noise. As the oxygen concentration was decreased NO emission decreased while $\mathrm{CO}$ emissions remained constant until instabilities were observed (at oxygen 235 concentration lower than about 13.8\%) [16].

These images provide a global description of how the reaction zone changes with different diluents and oxygen concentration reduction. To further understand the reaction behavior and distribution, chemiluminescence emission signal was captured at different wavelengths (specific to $\mathrm{OH}^{*}$ and $\mathrm{CH}^{*}$ ). The obtained images are shown in Fig. 3 for filter wavelengths of $307 \mathrm{~nm}$

$240\left(\mathrm{OH}^{*}\right)$ and $430 \mathrm{~nm}\left(\mathrm{CH}^{*}\right)$. The images obtained at 410 and $450 \mathrm{~nm}$, that correspond to background noise and $\mathrm{CO}_{2} *$ chemiluminescence, are also given and are used here for background correction. 
The signals captured at $307 \mathrm{~nm}\left(\mathrm{OH}^{*}\right), 410 \mathrm{~nm}$ and $450 \mathrm{~nm}$ were corrected following equations (2-4) to account for different camera and filter efficiencies as compared to the signal captured at $245430 \mathrm{~nm}\left(\mathrm{CH}^{*}\right)$. The corrected signals are shown in Fig. 4 along with the raw $\mathrm{CH}^{*}$ signal scaled to the same scale.

By accounting for the different filter transmission efficiencies and camera quantum efficiency, one can obtain a corrected $\mathrm{CH}^{*}$ plot (corrected for background and $\mathrm{CO}_{2} *$ chemiluminescence) following equation (1). The corrected $\mathrm{CH}^{*}$ signal is then divided by 250 corrected $\mathrm{OH}^{*}$ signal to provide a measure of the equivalence ratio and reaction distribution within the reaction zone. A Matlab code was employed to handle the images subtraction and division with a subroutine to detect the image boundaries and correct for any shift that might have occurred during filter change and installation. Figure 5 shows the obtained $\mathrm{CH}^{*} / \mathrm{OH}^{*}$ ratio for the different dilution cases (oxygen concentrations of $21 \%$ to $13.8 \%$ ) at an equivalence ratio 255 of 0.9 with focus on the flame region.

Increase in the diluents amount (decrease in oxygen concentration) resulted inlower $\mathrm{CH}^{*} / \mathrm{OH}^{*}$ signal and that the signal emission distribution covered a larger portion of the combustor. For the case of no dilution, the $\mathrm{CH}^{*} / \mathrm{OH}^{*}$ ratio was between 0.4 and 0.6 with some local spots of higher values. As the oxygen concentration was decreased, this ratio decreased to 260 an average of 0.35 for oxygen concentration of $15.58 \%$. For oxygen concentration of $13.8 \%$, the ratio was widespread (as seen from Fig. 2 of the visible flame emission signatures,) with $\mathrm{CH}^{*} / \mathrm{OH}^{*}$ value of 0.2 or less.

Following the work of Muruganandamet al.[28], one can convert these ratios to equivalence ratios based on similarity in Reynolds number ( 10000) between their work and this study in the 
265 swirl combustor experiments. For the conversion, the data reported by Muruganandamet al. [28] was curve fitted and an equation relating the $\mathrm{CH}^{*} / \mathrm{OH}^{*}$ to equivalence ratio was given as:

$$
\text { Phi }=-1.1184\left(\mathrm{CH}^{*} / \mathrm{OH}^{*}\right)^{\wedge} 2+1.5361\left(\mathrm{CH}^{*} / \mathrm{OH}^{*}\right)+0.44
$$

where, Phi represents the equivalence ratio. This curve fit had a regression coefficient of 0.975 with a maximum difference of 5\% between measured values [28] and the calculated values from

270 equation (5). Figure 6 shows the respective equivalence ratios obtained by applying equation (5) to the data shown in Fig. 5.

For the case of no dilution, the equivalence ratio was 0.95 at its highest (at the swirl lobes) and decreased as one movedfurther downstream. This is expected from swirl flames wherein the flame is anchored at the shear layer in the central recirculation zone. As one movesfurther away

275 from this shear layer the reaction signature diminishes from the completed combustion due to the availability of excess air. It is noteworthy that the global equivalence ratio in this case is 0.9 ;however, the local ratio varies as air and fuel are injected in non-premixed method.Fuel is injected directly after the swirler and the reaction is expected to occur at an equivalence ratio close to stoichiometry (similar to a diffusion flame) regardless of the global equivalence ratio.

280 The deviation between the obtained value (0.95) and stoichiometry can be attributed to the mixing process between air and fuel jet.

Increase in the amount of diluents decreased the maximum value of the equivalence ratio (0.85 0.9 at oxygen concentrations of $17.89 \%$ and $16.65 \%)$. Further increase in diluents (decrease in oxygen concentration) resulted in a more distributed and uniform equivalence ratio 285 across the combustor with the reaction zone occupying a larger area. Also, at these lower oxygen concentration and increased dilution, the characteristic zones associated with swirl burners disappear and a more uniform and dispersed reaction zone occurs. At oxygen concentration of 
$15.58 \%$, the local equivalence ratio varied between 0.75 and 0.8 , while at the lowest oxygen concentration of $13.8 \%$ the local equivalence ratio average was about 0.68 .

290 To better characterize the reaction distribution, statistical analysis was performed on the obtained equivalence ratio. Figure 7 shows the variation of the mean and standard deviation with different dilution amounts and oxygen concentration. There is minimal variation in the mean value. This can be attributed to the fact that in high oxygen concentration (21\%), the high value of local equivalence ratio is offset by the lower values outside the flame zone. On the other hand 295 at low oxygen concentration, the values are closer to each other, with almost no zero values (due to the distributed flame nature) to result in a similar mean value. This is supported by the standard deviation values. At high oxygen concentration the standard deviation is high, indicating that values deviate from the mean with a greater extent, while it is low for the low oxygen concentration case, indicating a more uniform value, more close to the mean. This low 300 standard deviation outlines distributed reaction combustion demonstrated at low oxygen concentration.

It is important to note that, in all the cases, the oxygen to fuel ratio did not change since only the oxygen concentration (through addition of diluents) was reduced. Consequently, the obtained equivalence ratios discussed herein are not the actual equivalence ratios, but rather a 305 representation of the reaction behavior. In other words, by having oxygen concentration of $13.8 \%$ (through dilution) resulted in a flame behavior that are similar to that of a flame at an equivalence ratio of 0.68 as seen through $\mathrm{OH}^{*}$ and $\mathrm{CH}^{*}$ chemiluminescence. More importantly, with increased dilution, the variation of equivalence ratio was minimized with the reaction covering a larger volume with a better distribution and elimination of concentration reaction 310 zone such as that observed in the central recirculation zoneof swirl combustors. These 
characteristics are signatures of distributed reaction combustion that is desirable for ultra-low emissions and enhanced thermal field uniformity.

The experiments wereperformed at an equivalence ratio of 0.7 with focus on fuel-lean operation. Similar to the results discussed at equivalence ratio of 0.9 , the flame occupied larger

315 portion of the combustor as the oxygen concentration was decreased through dilution. Figure 8 shows the obtained equivalence ratio plots using $\mathrm{CH}^{*}$ and $\mathrm{OH}^{*}$ chemiluminescence. Although the global equivalence ratio was 0.7 , the air and fuel were injected in a non-premixed mode leading to reaction occurring at a different equivalence ratio other than the global one, leading to the higher measurement with no dilution case, where the measured equivalence ratio was close to

320 0.9. As the amount of diluents was increased, the maximum value of the equivalence ratio decreased from 0.9 (for oxygen concentrations of 21\%) down to 0.7 (at oxygen concentration of $16.5 \%)$. Moreover, the equivalence ratio variation decreased throughout the flame area leading to a distributed reaction for at low oxygen concentration. The mean of the signal decreased from 0.6819 to 0.6065 with decrease in oxygen concentration from $21 \%$ to $16.5 \%$ and the standard

325 deviation decreased from 0.1241 to 0.0648 for the same cases, demonstrating better distributed reaction at the lower oxygen concentration.

\subsection{Experiments with Diluents at Elevated Temperatures}

To examine the impact of diluents temperature on flame behavior at elevated temperatures,

330 the experiments were performed with diluents temperature at $600 \mathrm{~K}$. The heat load of the combustor was kept at $3.25 \mathrm{~kW}$ and air was supplied to the combustor to result in an equivalence ratio of 0.9 . The obtained $\mathrm{OH}^{*}$ and $\mathrm{CH}^{*}$ results were processed as outlined earlier to obtain the local equivalence ratios. Increase in the diluents temperature resulted in higher NO emission as 
compared to that obtained at diluents temperature of $300 \mathrm{~K}$ [16]. However, increase in the

335 diluents temperature allowed stable combustor operation at lower oxygen concentration (down to $10.73 \%$ as compared to $13.8 \%$ ) [16]. Figure 9 shows the equivalence ratio plots for diluents temperature of $300 \mathrm{~K}$ and $600 \mathrm{~K}$ at an equivalence ratio of 0.9 and oxygen concentration of $16.65 \%$.

As the diluent temperature was increased, the reaction area was enlarged, with higher signal

340 values across the combustor, as compared to the case of diluents injected at $300 \mathrm{~K}$. This increase in signal corresponds with the increase in pollutants emissionas reported previously [16].

Figure 10 shows the change in reaction behavior with increased dilution (decrease in oxygen concentration) at a diluent temperature of $600 \mathrm{~K}$. As the amounts of diluents increases, the reaction occupies a larger areaat lower local equivalence ratio. At oxygen concentration of

$34516.65 \%$, the maximum equivalence ratio was about 0.95 with an average of 0.89 . Further reduction in oxygen concentration resulted in lower maximum and mean values $(0.8$ and 0.72 at $\mathrm{O}_{2}$ of $13.8 \%, 0.75$ and 0.65 at $\mathrm{O}_{2}$ of $11.78 \%$ ). The standard deviation of the signal was also decreased from $0.126\left(\right.$ at $16.65 \% \mathrm{O}_{2}$ ) to 0.0686 (at $11.78 \% \mathrm{O}_{2}$ ) resulting in a better reaction distribution from improved distributed combustion conditions.

\section{$5.3 \quad N O *$ Chemiluminescence}

The chemiluminescence of NO was also obtained to determine its behavior with change in dilution and oxygen concentration. Figure 11 shows the NO signal, obtained at 248nm, as compared to the $\mathrm{OH}$ signal (at $307 \mathrm{~nm}$ ) for equivalence ratio of 0.9 with no dilution. The

355 difference between both signal intensity is significant with NO signal being almost one order of magnitude smaller than $\mathrm{OH}$ signal (for the same exposure time and gain). For both signals, the 
filters and camera had the same efficiency allowing direct comparison between the two signals.Note that for the NO signal $(248 \mathrm{~nm} \pm 15 \mathrm{~nm})$, the filter bandwidth is well outside the $\mathrm{OH}$ band around $283 \mathrm{~nm}$ (from the $(1,0)$ vibrational band), eliminating any possibility of $\mathrm{OH}$ 360 chemiluminescence present in the NO signal.

Figure 12 shows the change in both $\mathrm{OH}^{*}$ and $\mathrm{NO}$ chemiluminescence signal with change in dilution. As the dilution increases (and oxygen concentration decreases), both $\mathrm{OH}^{*}$ signal and NO signal decreased in intensity with a rather distributed nature as compared to their concentrated nature with no dilution. The signals are scaled differently for better signal detection

365 at high dilution and low oxygen concentration.Comparing both signals, one can see that the NO signal coincides with maximum $\mathrm{OH}^{*}$ signal. Also, both signals behave similarly in terms of occupying larger volume at decreased intensity at increased entrainment and reduced oxygen concentration. This behavior translated to a reduction in NO emission for the same conditions, from 13.3 PPM of $\mathrm{NO}\left(\right.$ at $21 \% \mathrm{O}_{2}$ ) to $2.23 \mathrm{PPM}$ of $\mathrm{NO}\left(\right.$ at $13.8 \% \mathrm{O}_{2}$ ) as reported previously [16] 370 and shown in Fig 13.

Experiments at lower equivalence ratio demonstrated the same trend whereinthe NO signal decreased with increase in dilution (reduction in oxygen), following the trend of $\mathrm{OH}^{*}$ chemiluminescence. This is evident from comparisonof the case with no dilution $\left(21 \% \mathrm{O}_{2}\right)$, wherein NO signal is recorded near the central recirculation zone, and with increased dilution

$375\left(18.5 \% \mathrm{O}_{2}\right)$, wherein $\mathrm{NO}$ signal was uniformly distributed throughout the reaction zone area. Further reduction in oxygen concentration did not affect the NO signal much. This can be attributed to the existing conditions for these cases.At these dilution amounts and oxygen concentration, thermal $\mathrm{NO}_{\mathrm{x}}$ is mitigated and the resulting $\mathrm{NO}$ emission is attributed to other $\mathrm{NO}_{\mathrm{x}}$ formation routes. This behavior was reflected through NO emissions, where NO was reduced 
380 from 6.6 PPM (at $21 \% \mathrm{O}_{2}$ ) to 2 PPM (at $18.5 \%$ O2) but only down to 1 PPM (at $16.5 \% \mathrm{O}_{2}$ ) as shown in Fig. 13. Figure 14 shows the recorded NO chemiluminescence signalemission for the discussed cases.

Experiments performed at higher diluents temperature demonstrated the same behavior wherein $\mathrm{NO}$ signal followed the trend of $\mathrm{OH}^{*}$ chemiluminescence in terms of maximum 385 concentration and distribution with increased dilution. The NO signal recorded agrees with the previously recorded emissions. NO emissions decreased from 13.3 PPM NO at no dilution down to 1.6 PPM for oxygen concentration of $11.78 \%$, see Fig 13 . Figure 15 shows the recorded NO chemiluminescencesignal for these cases, where the concentrated NO signal at the recirculation zone (for no dilution) disappears with increased dilution to result in distributed low NO signal at

390 low oxygen concentration.

\section{Conclusions}

Experiments performedat different reduced oxygen concentration in the fresh mixture, at a global equivalence ratio of 0.9 , provided significant change to the reaction behavior. For the case

395 of normal air (no dilution), the reaction zone was concentrated near the central recirculation zone of the swirler. The swirl characteristics disappeared with increase in the amounts of dilution, to result in a more distributed reaction zone occupying larger volume of the combustor. $\mathrm{CH}^{*} / \mathrm{OH}^{*}$ was used to obtain a representation of local equivalence ratio for the different cases. As the oxygen concentration was decreased, the maximum equivalence ratio decreased with the mean

400 approaching the maximum value along with a lower standard deviation of the signal. Closer mean to maximum signal, coupled with lower standard deviation for the equivalence ratio indicates improved distributed reaction conditions. These conditions were fostered at oxygen 
concentration of $15 \%$ and lower. This oxygen concentration is approximately where the swirl characteristics disappear resulting in improved distributed reactions. Similar behavior was

405 demonstrated at lower equivalence ratio of 0.7 . With diluents preheated to $600 \mathrm{~K}$, the reaction transformed to distributed combustion regime upon lowering of the oxygen concentration.Higher temperature of the diluents allowed stable combustion at lower oxygen concentration.

Chemiluminescence signaloutlined the presence of NO in the reaction zone with reduced signal intensity at increased dilution. The NO signal followed the maximum $\mathrm{OH}^{*}$ signal in

410 location and behavior. Reducing oxygen concentration led to lower NO distribution in the combustor

The obtained data on local equivalence ratio (as well as uniform $\mathrm{CH}^{*} / \mathrm{OH}^{*}$ signal) and $\mathrm{NO}$ emission (quantified through NO light emission and emission measurement suggests that to foster distributed combustion conditions (CDC), oxygen concentration of $15 \%$ is favored in the

415 fresh mixture. Such oxygen concentration will dictate the required internal entrainment ratio at a given combustion operation.

\section{Acknowledgments}

This research was supported by ONR and is gratefully acknowledged.

\section{References}

[1] Arghode VK, and Gupta AK. Effect of Flow Field for Colorless Distributed Combustion (CDC) For Gas Turbine Combustion. J. Applied Energy 2010;87:1631-1640.

[2] Khalil AEE,and Gupta AK. Swirling Distributed Combustion for Clean Energy 425 Conversion In Gas Turbine Applications. J. Applied Energy, 2011:88:3685-3693. 
[3] Khalil AEE,and Gupta AK. Distributed Swirl Combustion for Gas Turbine Application. J. Applied Energy, 2011;88:4898-4907.

[4] Khalil AEE, and Gupta, AK. Fuel Flexible Distributed Combustion With Swirl for Gas Turbine Applications. J. Applied Energy, 2013;109:327-334.

430 [5] Khalil AEE, and Gupta, AK. Hydroxyl Radical Distribution for Colorless Distributed Combustion Conditions. Fuel, 2014;122:28-35.

[6] Khalil AEE, Gupta AK, Bryden MK, Lee SC. Mixture Preparation Effects on Distributed Combustion for Gas Turbine Applications. J. Energy Resour. Technol., 2012;134(3):032201.

[7] Khalil AEE,and Gupta AK. Dual Injection Distributed Combustion for Gas Turbine 435 Application. J. Energy Resour. Technol., 2014;136(1):011601.

[8] Khalil AEE, and Gupta, AK. Velocity and Turbulence Effects on High Intensity Distributed Combustion. J. Applied Energy, 2014;125:1-9.

[9] Khalil AEE, Arghode, VK, Gupta, AK. Novel Mixing for Ultra-High Thermal Intensity Distributed Combustor. J. Applied Energy, 2013;105:327-334.

440 [10] Correa SM. A Review of NOx Formation under Gas-Turbine Combustion Conditions. Combustion Science and Technology, 1992;87:329-362.

[11] Tsuji H, Gupta AK, Hasegawa T, Katsuki M, Kishimoto K, Morita M. High temperature air combustion: from energy conservation to pollution reduction. Boca Raton, Florida: CRC Press; 2003.

445 [12] Gupta AK. Thermal Characteristics of Gaseous Fuel Flames Using High Temperature Air. J. Eng. Gas Turbines Power, 2004;126(9):pp. 9-19. 
[13] Kitagawa K, Konishi N, Arai N, and Gupta AK. Temporally Resolved 2-D Spectroscopic

Study on the Effect of Highly Preheated and Low Oxygen Concentration Air on Combustion. J. Eng. Gas Turbines Power, 2003;125:326-331.

450 [14] ElKady AM, Evulet A, Brand A, Ursin TP, Lynghjem A. Exhaust Gas Recirculation in DLN F-Class Gas Turbines for Post-Combustion $\mathrm{CO}_{2}$ Capture. Proceedings of ASME Turbo Expo 2008: Power for Land, Sea and Air, GT2008, June 9-13, 2008, Berlin, Germany, Paper GT2008-51152.

[15] Evulet A, ElKady AM, Brand A, Chinn D.On the Performance and Operability of GE's 455 Dry Low NOx Combustors utilizing Exhaust Gas Recirculation for Post-Combustion Carbon Capture. Energy Procedia, 2009;1:3809-3816.

[16] Khalil AEE, and Gupta, AK. Impact of Internal Entrainment on High Intensity Distributed Combustion. J. Applied Energy, 2015;156:241-250.

[17] Kojima J, Ikeda Y, Nakajima T. Spatially Resolved Measurment of $\mathrm{OH}^{*}, \mathrm{CH}^{*}$ and C2* 460 Chemiluminescence in the Reaction Zone of Laminar Methane/Air Premixed Flames. Proc. Of Combust. Inst., 2000;28:1757-1764.

[18] Ikeda Y, Kojima J, Hashimoto H, Nakajima T. Detailed Local Spectra Measurment in High-Pressure Premixed Laminar Flame. Proc. Of the $40^{\text {th }}$ Aerospcace Sciences Meeting \& Exhibit, 14-17 January 2002, Reno, Nevada. Paper\# AIAA-2002-0191.

465 [19] Kojima J, Ikeda Y, Nakajima T. Chemiluminescence Based Local Equivalence Ratio Measurementt in Turbulent Premixed Flames. Proc. Of the $40^{\text {th }}$ Aerospcace Sciences Meeting \& Exhibit, 14-17 January 2002, Reno, Nevada. Paper\# AIAA-2002-0193.

[20] Brown MS, Meyer TR, Sturgess GJ, Zelina J, Gord JR. Chemiluminesence as a Measurement of Local Equivalence Ratio. Proc. Of the $38^{\text {th }}$ AIAA/ASME/SAE/ASEE Joint 
470 Proulsion Conference \& Exhibit, 7-10 July 2002, Indianapolis, Indiana. Paper\# AIAA-20023865.

[21] Hardalupas Y, Orain M. Local Measurements of the Time-Dependent Heat Release Rate and Equivalence Ratio Using Chimiluminescent Emission from a Flame. Combustion and Flame, 2004;139:188-207.

475 [22] Jeong YK, Jeon CH, Chang YJ. Evaluation of the Equivalence Ratio of the Reacting Mixture using Intensity Ratio of Chemiluminescence in Laminar Partially Premixed CH4-Air Flames. Expermintal Thermal and Fluid Sciences, 2006;30:663-673

[23] Nori VN, Seitzman JM. CH* Chemiluminescence Mdoeling for Combustion Diagnostics. Proc. Of Combust. Inst., 2009;32:895-903.

480 [24] Tripathi MM, Krishnan SR, Srinivasan KK, Yueh FY, Singh JP. ChemiluminescenceBased Multivariate Sensing of Local Equivalence Ratios in Premixed Atmospheric Methane-Air Flames. Fuel, 2012;93:684-691.

[25] Morell MR, Seitzman JM, Wilensky M, Lubarsky E, Lee J, Zinn B. Interpretation of Optical Emissions for Senesors in Liquid Fueled Combustos. Proc. Of the $39^{\text {th }}$ Aerospcace 485 Sciences Meeting \& Exhibit, 8-11 January 2001, Reno, Nevada. Paper\# AIAA-2001-0787.

[26] Muruganandam TM, Kim B, Olsen R, Patel M, Romig B, Seitzman JM. Chemiluminescnec Based Sensors for Turbine Engines. Proc. Of the $39^{\text {th }}$ AIAA/ASME/SAE/ASEE Joint Proulsion Conference \& Exhibit, 20-23 July 2003, Huntsville, Alabama. Paper\# AIAA-2003-4490.

490 [27] Cheng TS, Wu CY, Li YH, Chao YC. Chemiluminescence Measurement of Local Equivalence Ratio in a Partially Premixed Flame. Combust. Sci. Technol., 2006;178:1821-1841. 
[28] Muruganandam TM, Kim BH, Morell MR, Nori V, Patel M, Romig BW, Seitzman JM. Optical Equivalence Ratio Sensors for Gas Turbine Combustors. Proc. Of the Combust. Inst., 2005;30:1601-1609.

495 [29] Guyot D, and Lacarelle A. $\mathrm{CH}^{*} / \mathrm{OH}^{*}$ Chemiluminesence Response of an Atmospheric Premixed Flame under Varying Operating Conditions. Proceedings of ASME Turbo Expo 2010: Power for Land, Sea and Air, GT2010, June 14-18, 2010, Glasgow, UK. Paper\# GT2010-23135.

[30] Docquier N, Lacas F, Candel S. Closed Loop Equivalence Ratio Control of Premixed Combustors using Spectrally Resolved Chemiluminescence Measurements. Proc. Combust. Inst., $500 \quad 2002 ; 29: 139-245$.

[31] Ravikrishna RV, Laurendeau NM. Laser-Induced Fluorescence Measurements and Modeling of Nitric Oxide in Methane-Air and Ethane-Air Counterflow Diffusion Flames. Combustion and Flame, 2000;120:372-382.

[32] Charlston-Goch D, Chadwick BL, Morrison RJS, Campisi A, Thomsen DD, Laurendeau 505 NM. Laser Induced Fluorescence Measurments and Modeling of Nitric Oxide in Premixed Flames of $\mathrm{CO}+\mathrm{H} 2+\mathrm{CH} 4$ and Air at High Pressures. Combustion and Flame, 2001;125:729-743.

[33] Kychakoff F, Knapp K, Howe RD, Hanson RK. Flow Visualization in Combustion Gases using Nitric Oxide Fluorescence. AIAA Journal, 1984;22(1):153-154

[34] Sutton J, and Driscoll JF. Imaging of Local Flame Extinction due to the Interaction of 510 Scalar Dissipation Layers and the Stoichiometric Contour in Turbulent Non-premixed Flames. Proc. Of the Combustion Institute, 2007;31(1):1487-1495.

[35] Pearse RWB, and Gaydon AG. The Identification of Molecular Spectra. London, UK: Chapman \& Hall LTD; $3^{\text {rd }}$ edition, 1963. 
[36] Luque J,and Crosley DR. LIFBASE, Database and Spectral Simulation for Diatomic 515 Molecules (v. 1.6). SRI International Report MP 99-009, 1999.

[37] Kim HS, Arghode VK, Linck MB, Gupta AK. Hydrogen Addition Effects in a Confined Swirl-Stabilized Methane-Air Flame. Int'1 J. Hydrogen Energy, 2009;34(2):1054-1062.

[38] Kim HS, Arghode VK, Gupta AK. Flame Characteristics of Hydrogen-Enriched Methane-Air Premixed Swirling Flames. Int'1 J. Hydrogen Energy, 2009;34(2):1063-1073. 


\section{Figure Captions}

Figure 1. Experimental test rig with flame using standard air (left) and reduced oxygen concentrations (right)

Figure 2. Flame images for different oxygen concentration (with change in diluents amount) for an equivalence ratio of 0.9

Figure 3. Acquired signal for no dilution case at an equivalence ratio of 0.9 for the different filters used Figure 4. Acquired signal for no dilution case at an equivalence ratio of 0.9 corrected for different filter and camera efficiencies

Figure 5. $\mathrm{CH}^{*} / \mathrm{OH}^{*}$ chemiluminescence signal at an equivalence ratio of 0.9 for different dilution cases (oxygen concentration variation from $21 \%$ to $13.8 \%$ )

Figure 6. Local equivalence ratio obtained from equation 5 for different dilution cases (oxygen concentration variation from $21 \%$ to $13.8 \%$ ) at a global equivalence ratio of 0.9

Figure 7. Mean and standard deviation of the equivalence ratio for different dilution cases (oxygen concentrations variation from $21 \%$ to $13.8 \%$ ) at a global equivalence ratio of 0.9

15 Figure 8. Local equivalence ratio as obtained from equation 5 for different dilution cases (oxygen concentrations variation from $21 \%$ to $16.51 \%$ ) at a global equivalence ratio of 0.7

Figure 9. Local equivalence ratio as obtained from equation 5 for $300 \mathrm{~K}$ (left) and $600 \mathrm{~K}$ (right) dilution temperature at a global equivalence ratio of 0.9

Figure 10. Local equivalence ratio as obtained from equation 5 at a global equivalence ratio of 0.9 and $600 \mathrm{~K}$ diluents temperature

Figure 11. $\mathrm{OH}^{*}$ and NO signal at an equivalence ratio of 0.9 with no dilution

Figure 12. $\mathrm{NO}$ (top row) and $\mathrm{OH}^{*}$ (bottom row) chemiluminescence signal with increased dilution (decreased oxygen concentration) at an equivalence ratio of 0.9 
Figure 13. NO emission for equivalence ratio of 0.9 at 300 and $600 \mathrm{~K}$, and equivalence ratio of 0.7 at

$25300 K[16]$

Figure 14. NO chemiluminescence signal with increased dilution (decreased oxygen concentration) at an equivalence ratio of 0.7

Figure 15. NO chemiluminescence signal with increased dilution (decreased oxygen concentration) at an equivalence ratio of 0.9 for diluents temperature of $600 \mathrm{~K}$

Table Captions

Table 1. Experimental parameters 


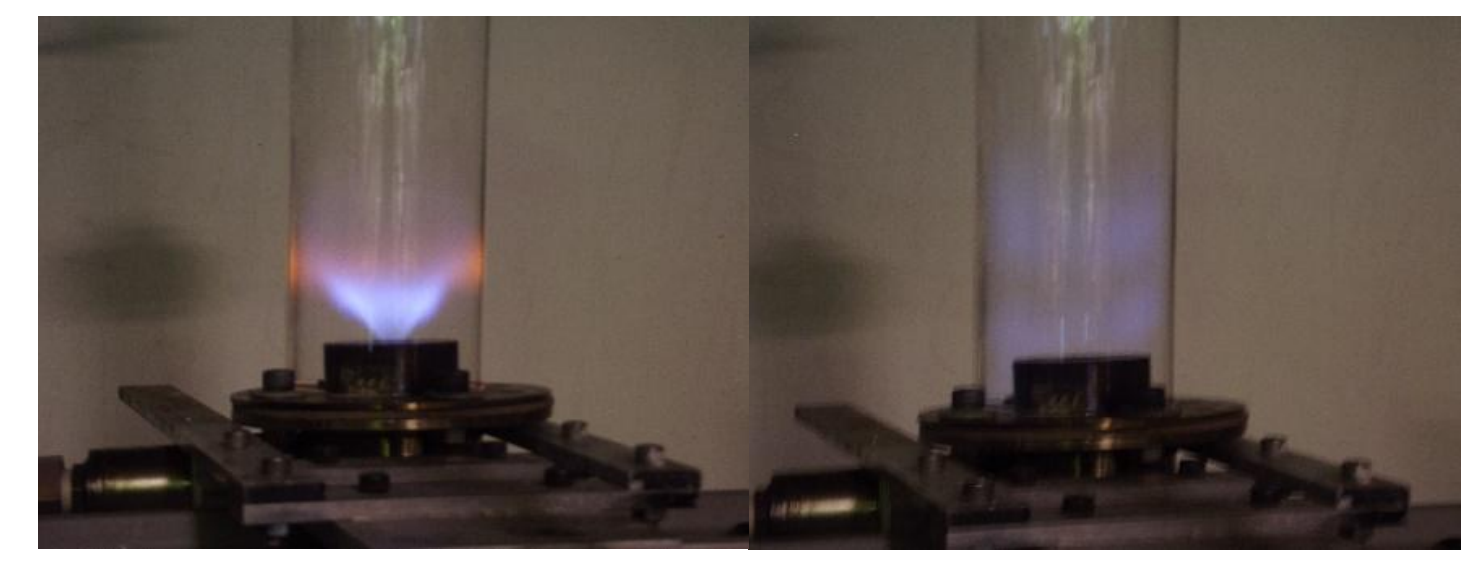

Figure 1. Experimental test rig with flame using standard air (left) and reduced oxygen concentrations (right)

\section{Eire}

Figure 1. Experimental test rig with flame using standard air (left) and reduced oxygen concentrations (right)

t)

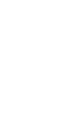




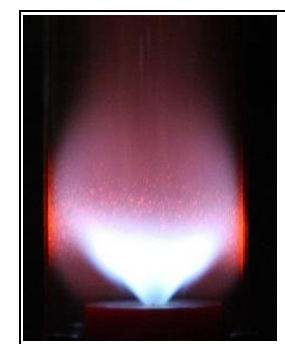

\begin{tabular}{|c|c|c|c|c|c|}
\hline & \\
\hline
\end{tabular}

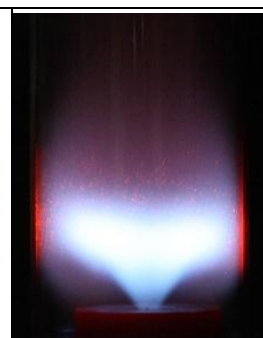

\begin{tabular}{|c|c|c|c|c|c|}
\hline & \\
\hline
\end{tabular}

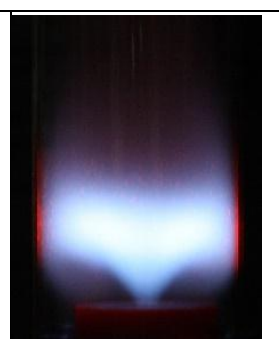

\begin{tabular}{|c|c|c|c|c|c|}
\hline & \\
\hline
\end{tabular}

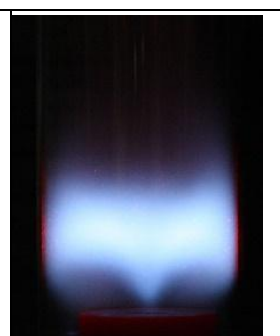

\begin{tabular}{|c|c|c|c|c|c|}
\hline & \\
\hline
\end{tabular}

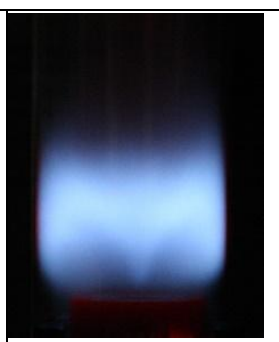

\begin{tabular}{|c|c|c|c|c|c|}
\hline & \\
\hline
\end{tabular}

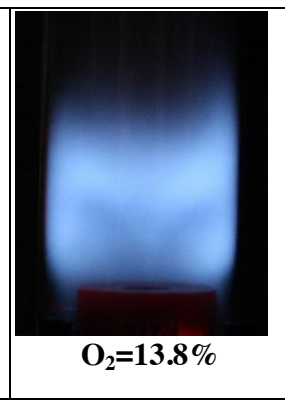

\begin{tabular}{|c|c|c|c|c|c|}
\hline & \\
\hline
\end{tabular}

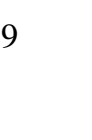




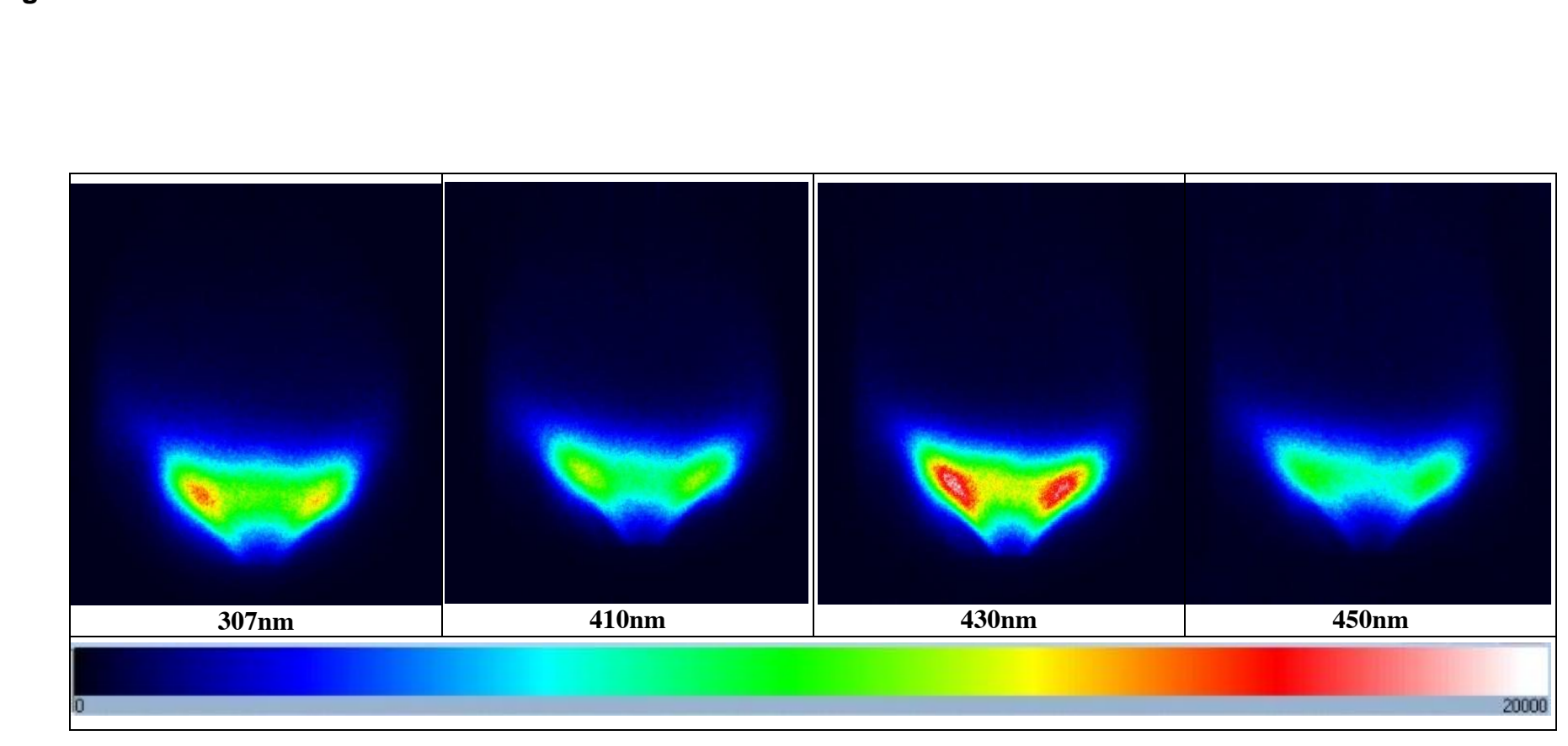

\begin{tabular}{l} 
Figure3 \\
\hline 307nm
\end{tabular}

(l)

(2)

20000

(1)

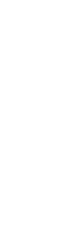

.

Figure 3 . cquired signa for no dilution case at an equ

.

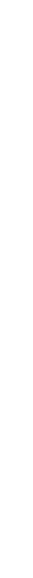




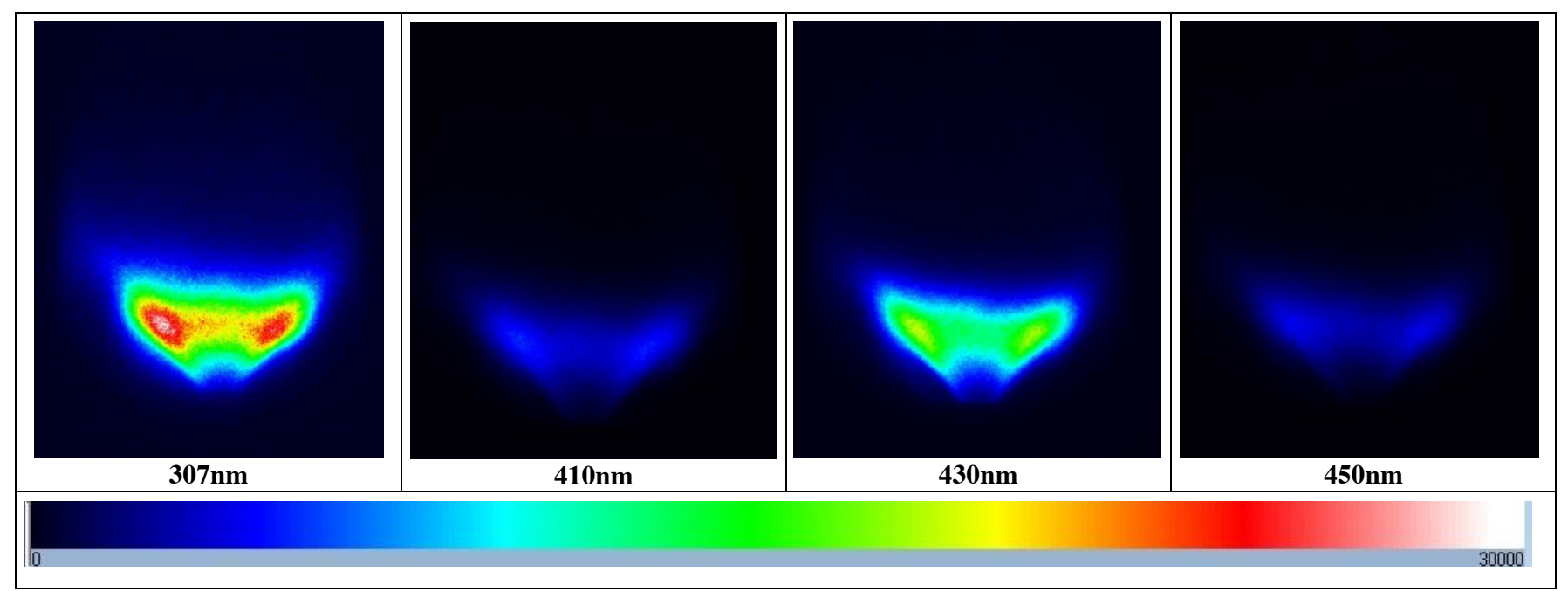

Figure 4. Acquired signal for no dilution case at an equivalence ratio of 0.9 corrected for different filter and camera efficiencies 


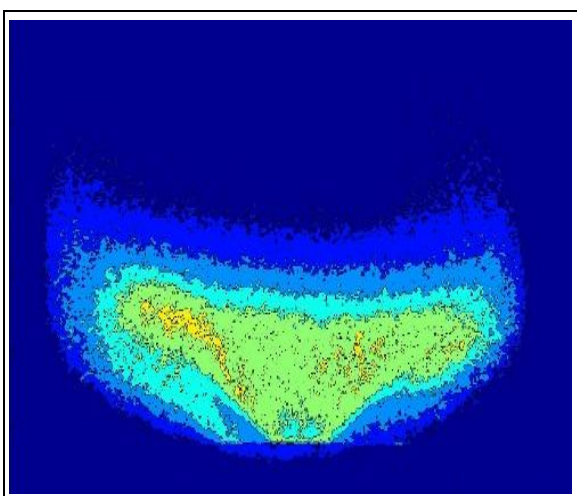

Phi=0.9, 21\% $\mathrm{O}_{2}$

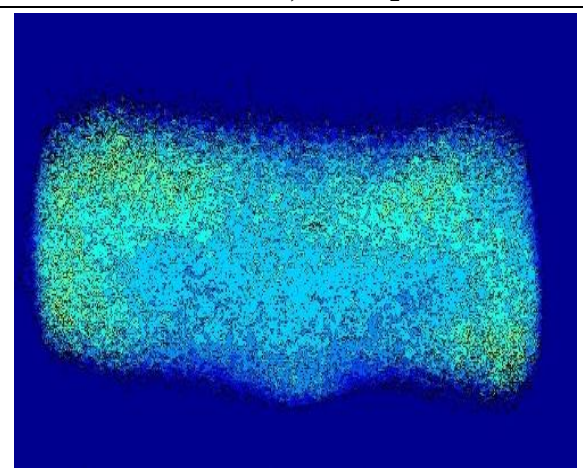

Phi=0.9, 15.58\% $\mathrm{O}_{2}$

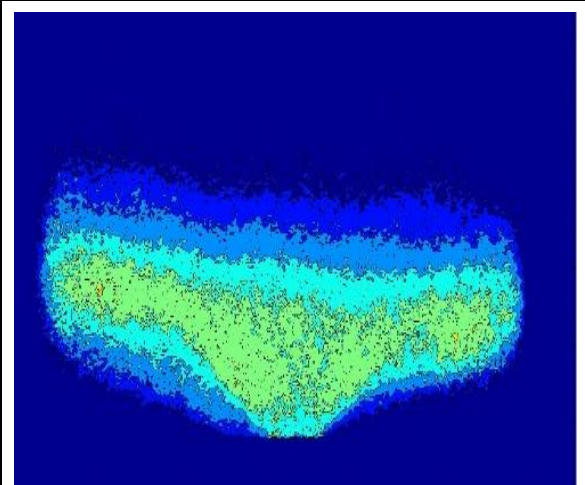

Phi=0.9, 17.89\% $\mathrm{O}_{2}$

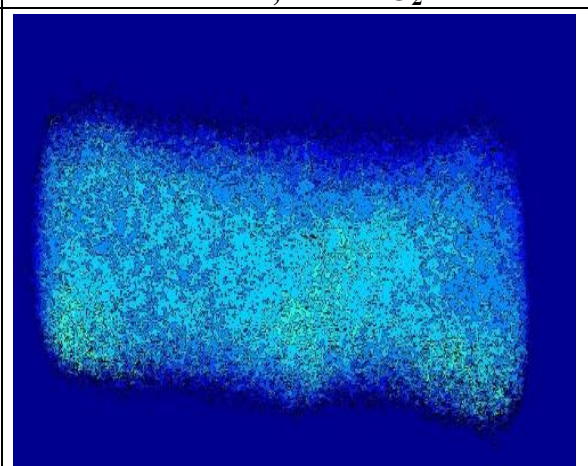

Phi=0.9, 14.64\% $\mathrm{O}_{2}$

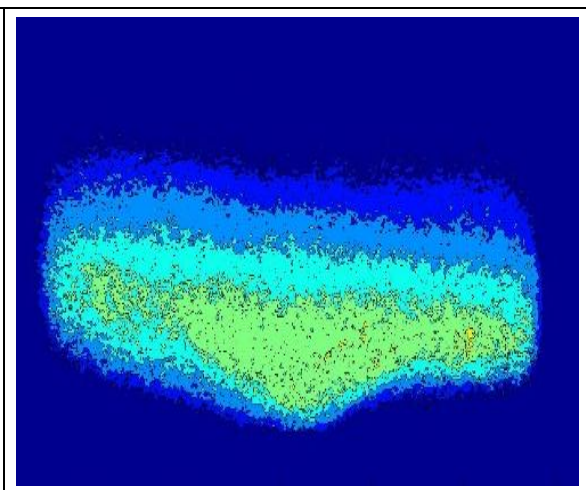

Phi=0.9, 16.65\% $\mathrm{O}_{2}$

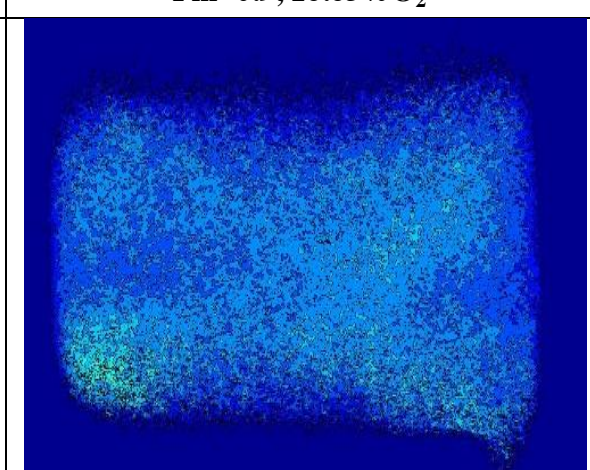

Phi=0.9, 13.8\% $\mathrm{O}_{2}$

0.1

0.3

0.4

0.7

Figure 5. $\mathrm{CH}^{*} / \mathrm{OH}^{*}$ chemiluminescence signal at an equivalence ratio of 0.9 for different dilution cases (oxygen concentration variation from $21 \%$ to $13.8 \%$ ) 


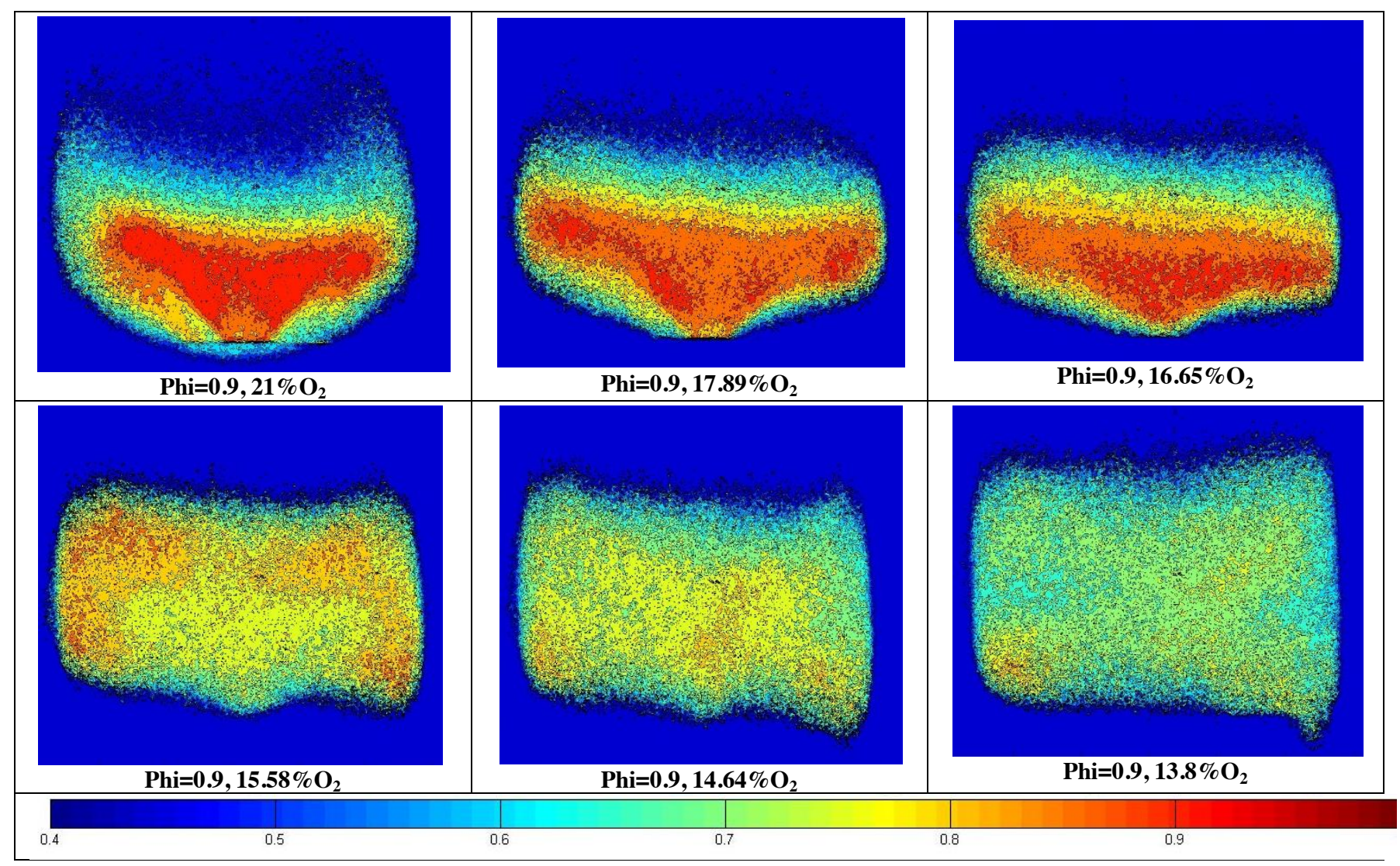

Figure 6. Local equivalence ratio obtained from equation 5 for different dilution cases (oxygen concentration variation from $21 \%$ to $13.8 \%$ ) at a global equivalence ratio of 0.9 


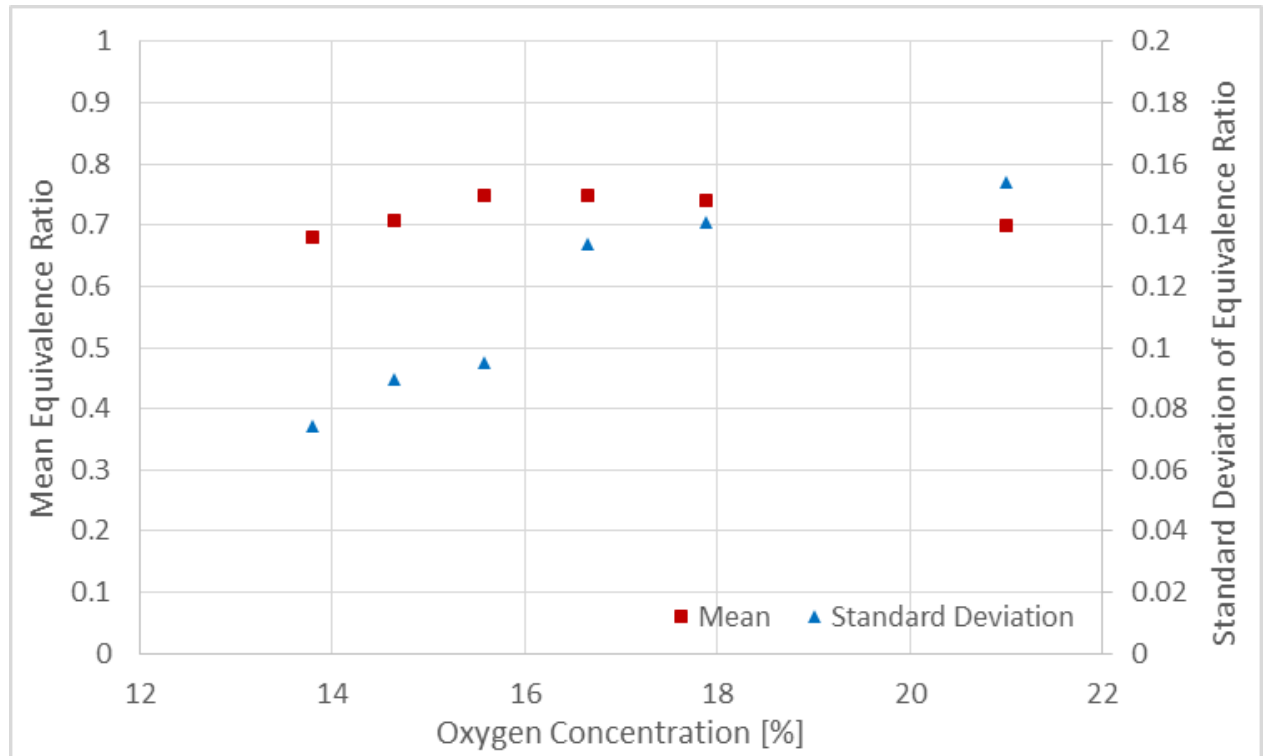

Figure 7. Mean and standard deviation of the equivalence ratio for different dilution cases (oxygen concentrations variation from $21 \%$ to $13.8 \%$ ) at a global equivalence ratio of 0.9 


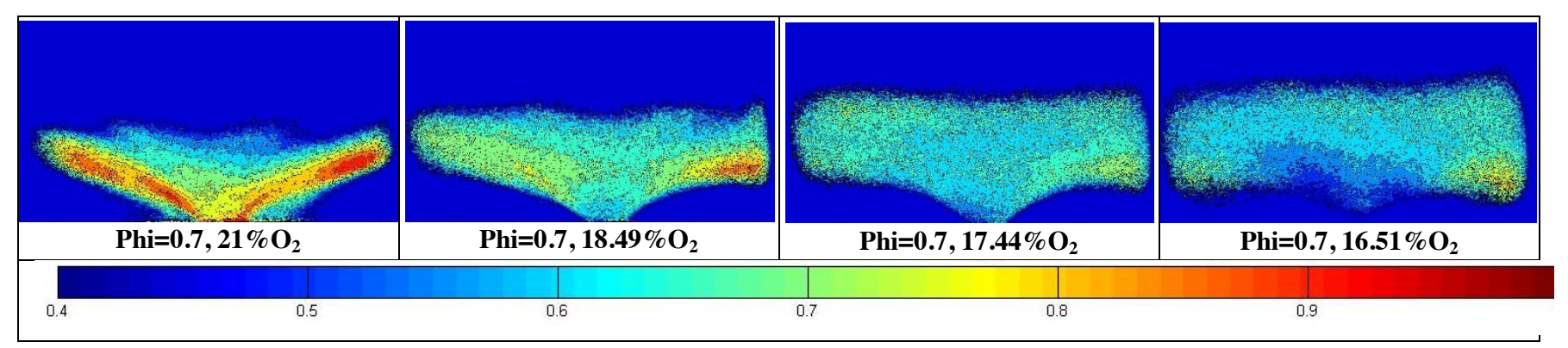

Figure 8. Local equivalence ratio as obtained from equation 5 for different dilution cases (oxygen concentrations variation from $21 \%$ to $16.51 \%$ ) at a global equivalence ratio of 0.7 


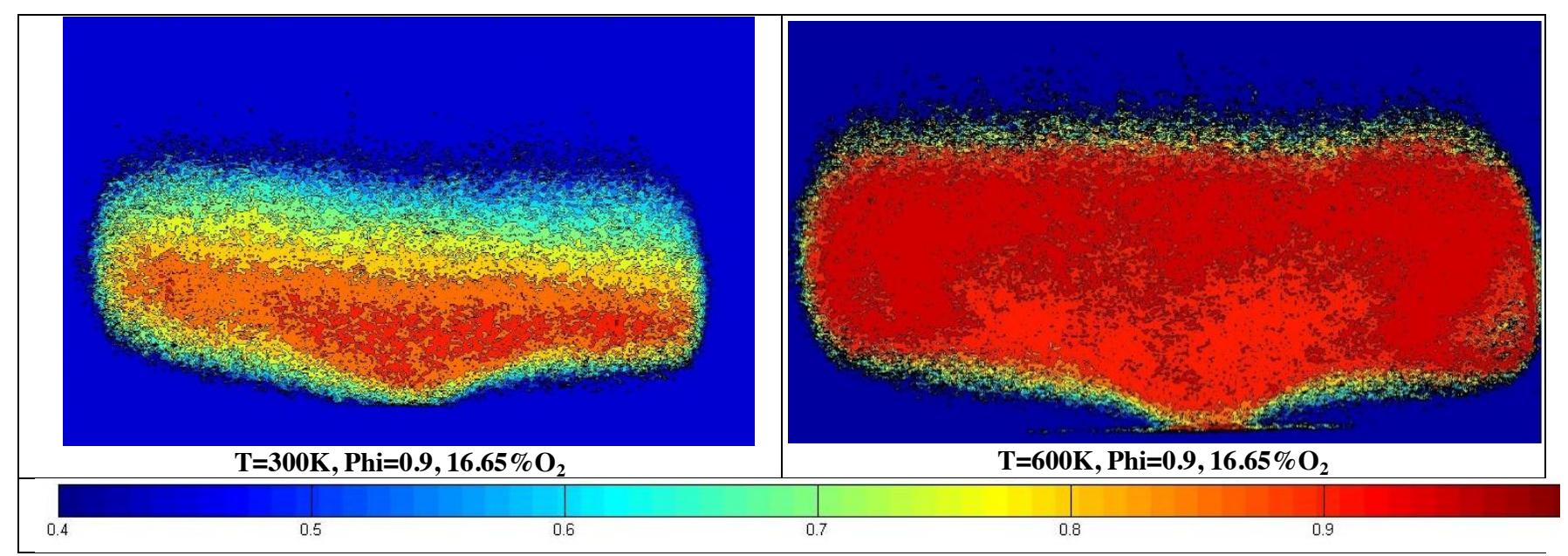

Figure 9. Local equivalence ratio as obtained from equation 5 for $300 \mathrm{~K}$ (left) and $600 \mathrm{~K}$ (right) dilution temperature at a global equivalence ratio of 0.9 


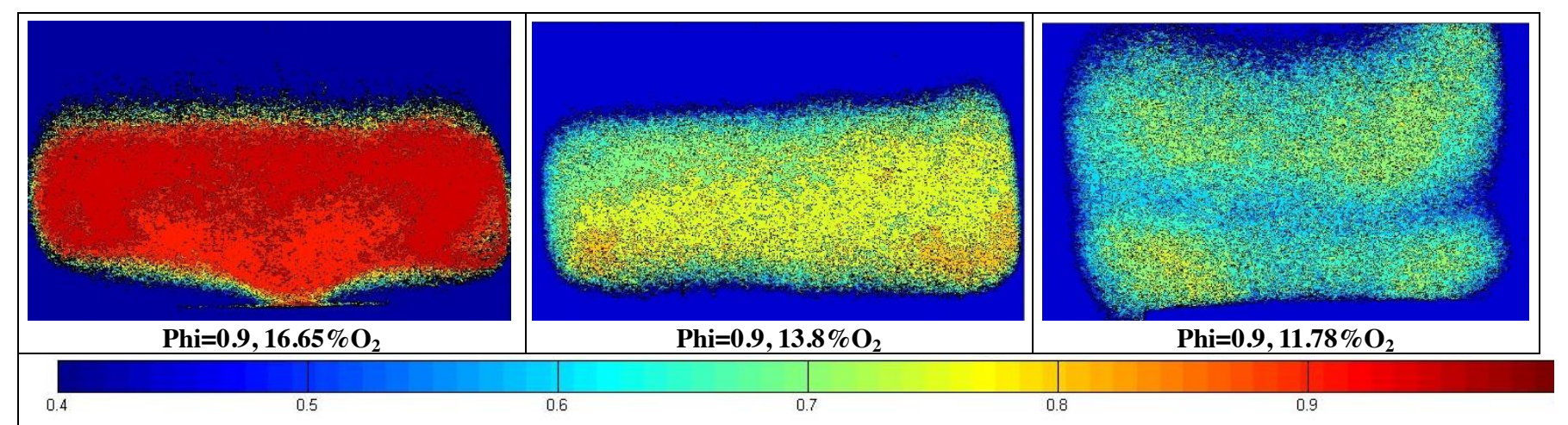

Figure 10. Local equivalence ratio as obtained from equation 5 at a global equivalence ratio of 0.9 and $600 \mathrm{~K}$ diluents

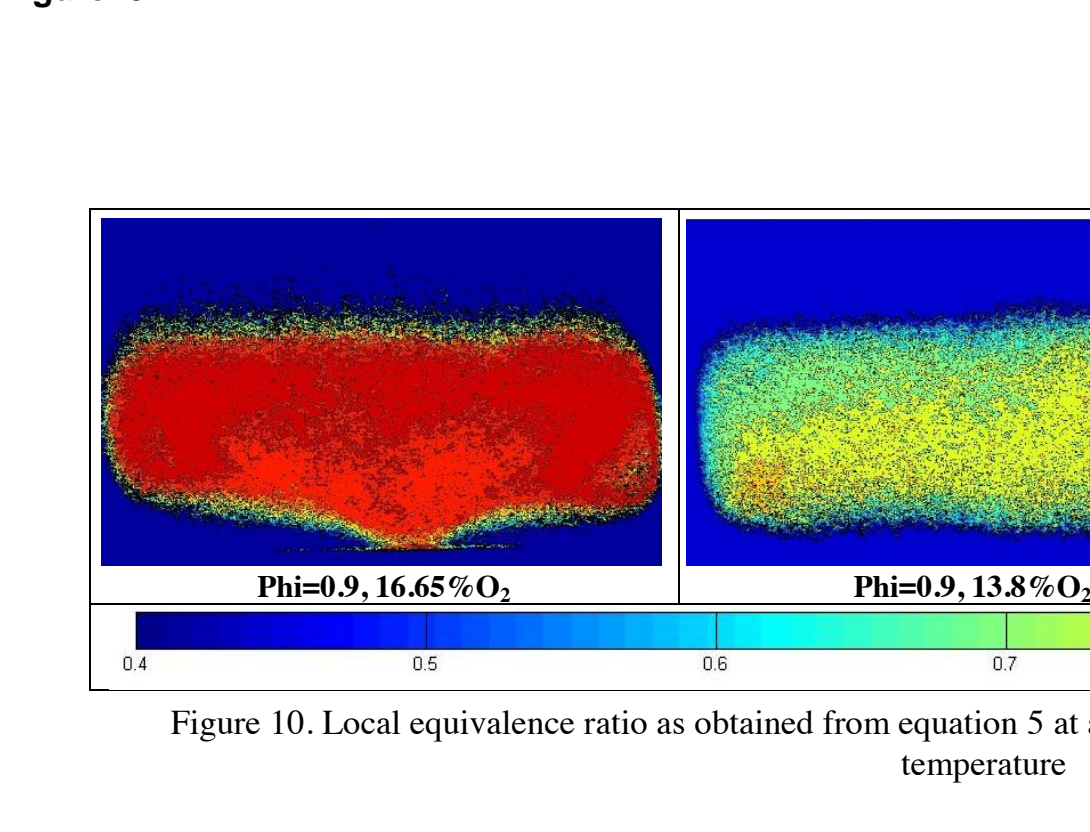

Phi=0.9, 11.78\% $\mathrm{O}_{2}$

0.9

(1)

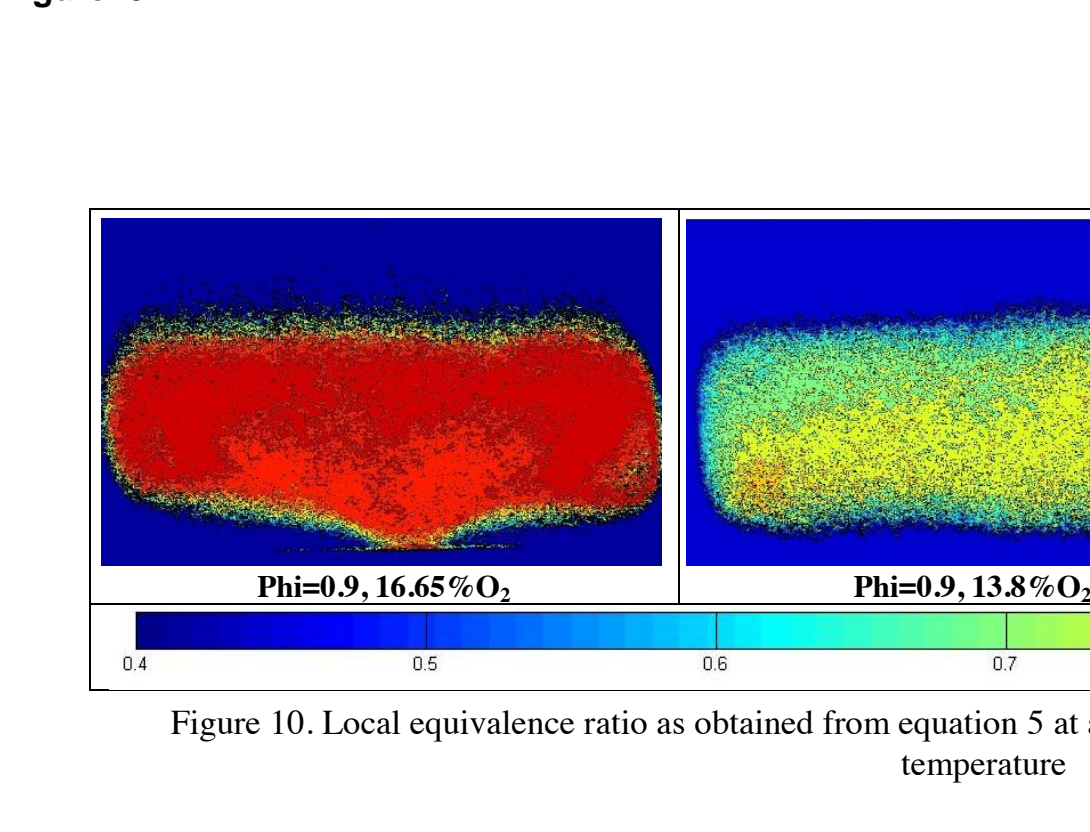




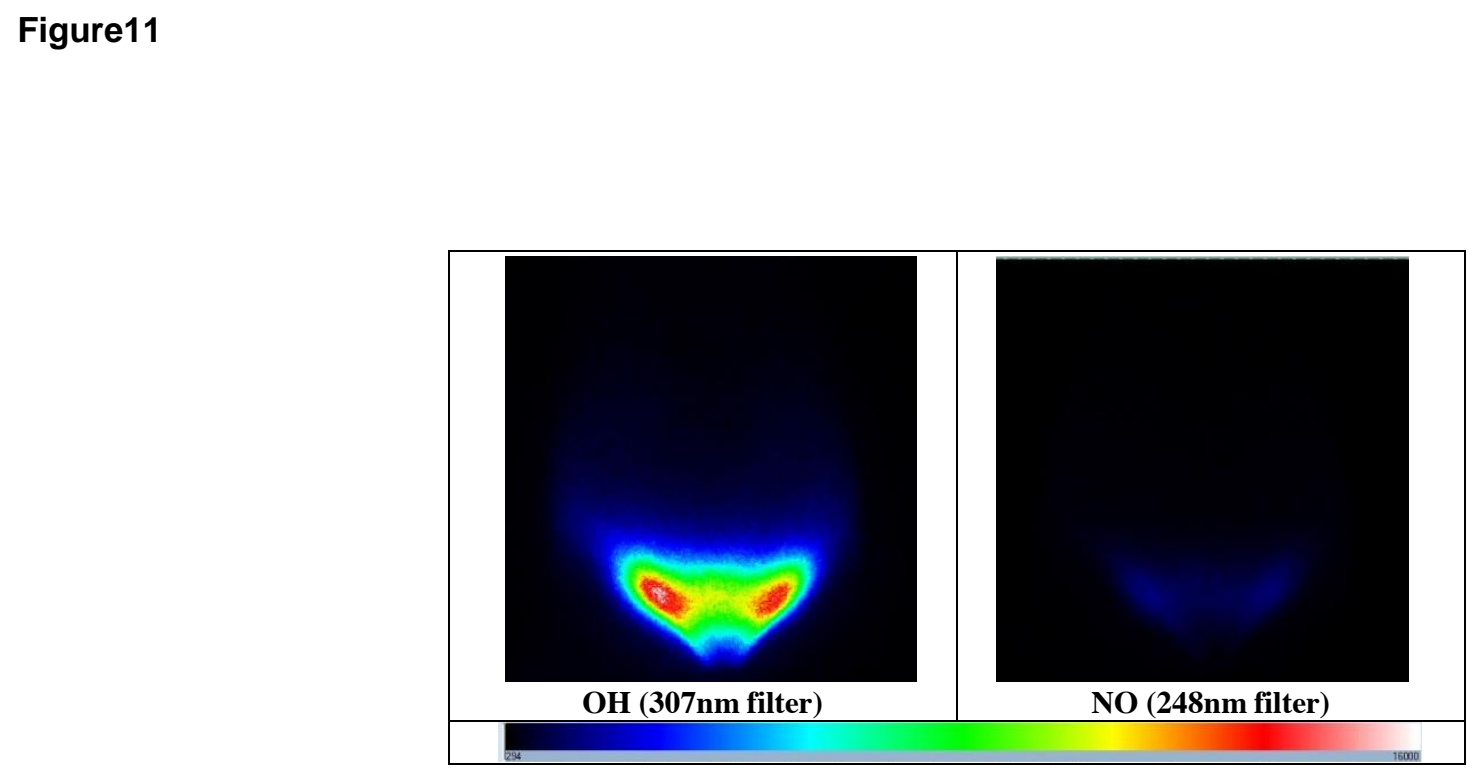

\begin{tabular}{l} 
Figure11 \\
$\qquad$\begin{tabular}{|l|l|l|}
\hline & \\
\hline FH (307nm filter) & \\
\hline
\end{tabular} \\
\hline
\end{tabular}

(1)

(1)




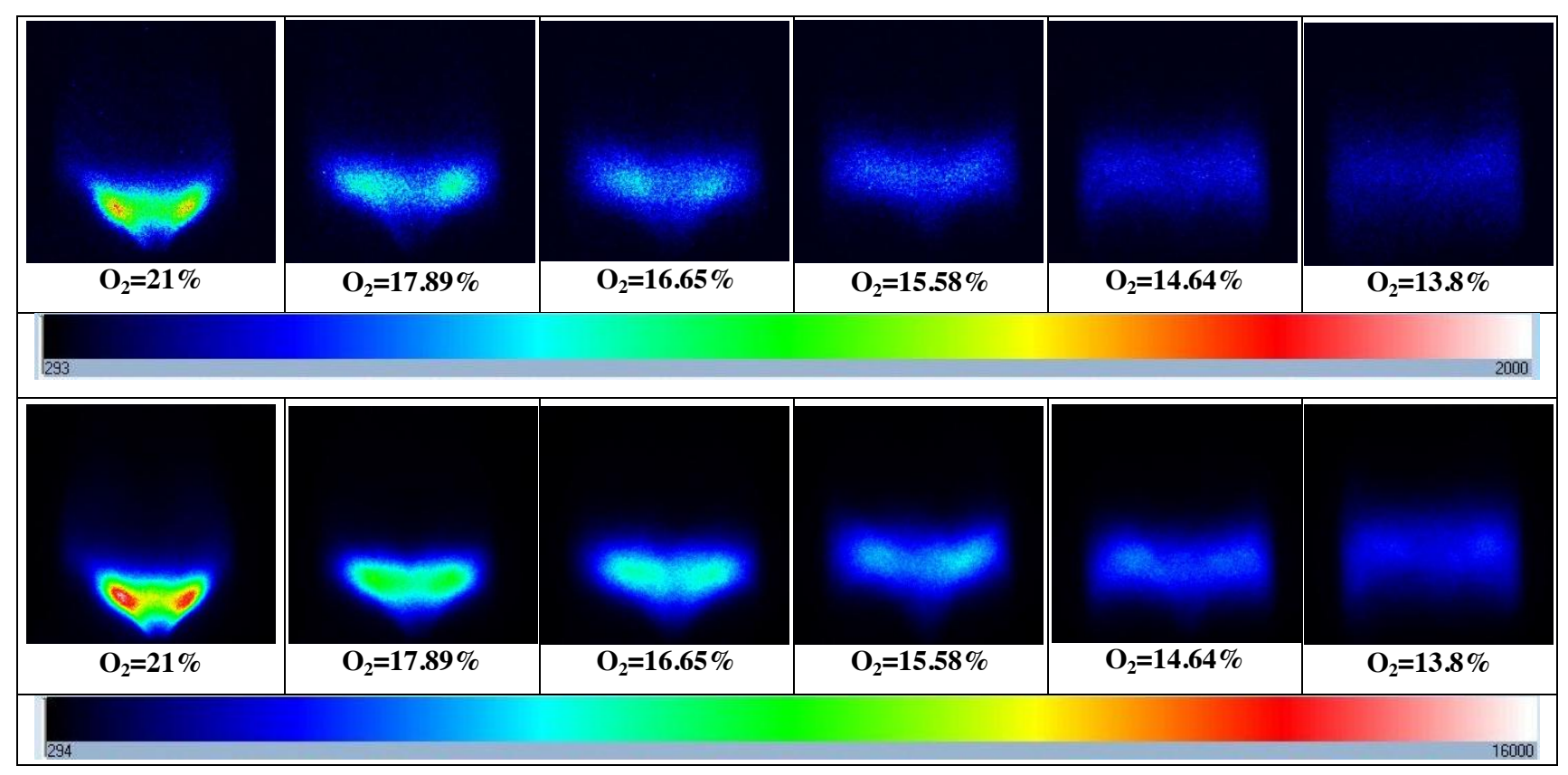

Figure 12. NO (top row) and $\mathrm{OH}^{*}$ (bottom row) chemiluminescence signal with increased dilution (decreased oxygen concentration) at an equivalence ratio of 0.9 


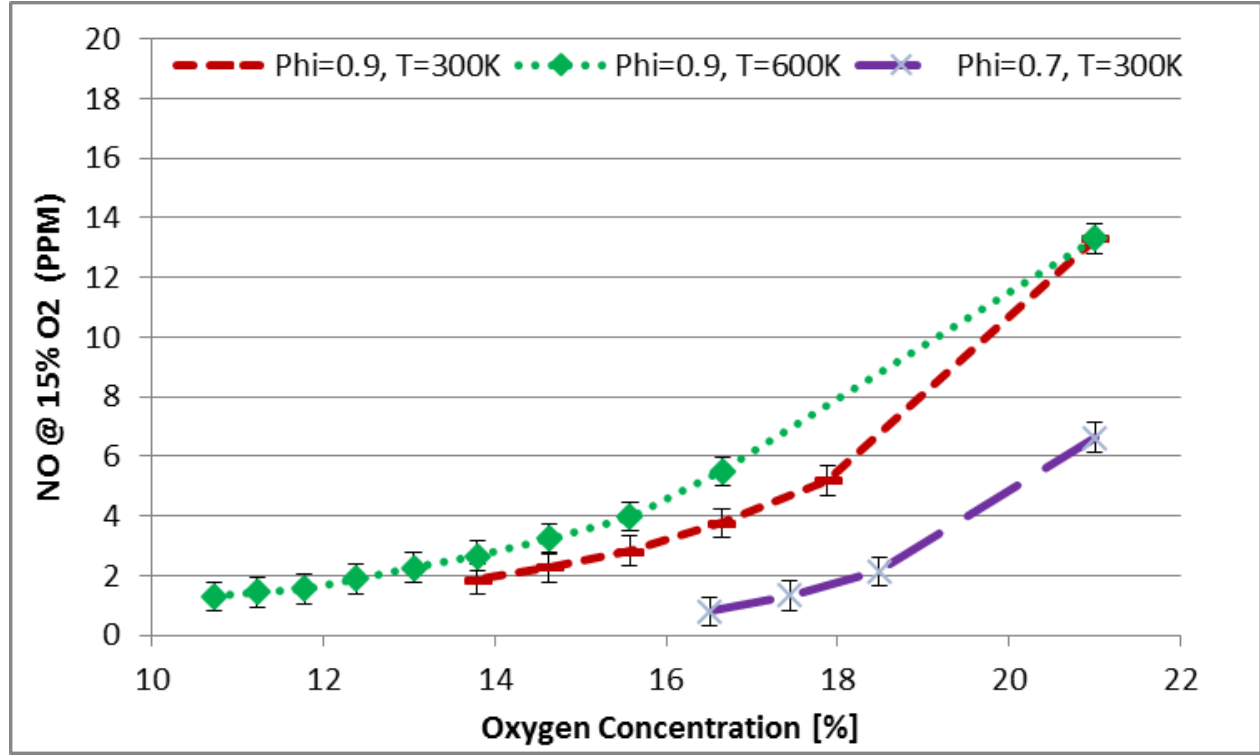

Figure 13. NO emission for equivalence ratio of 0.9 at 300 and $600 \mathrm{~K}$, and equivalence ratio of 0.7 at $300 \mathrm{~K}$ [16] 


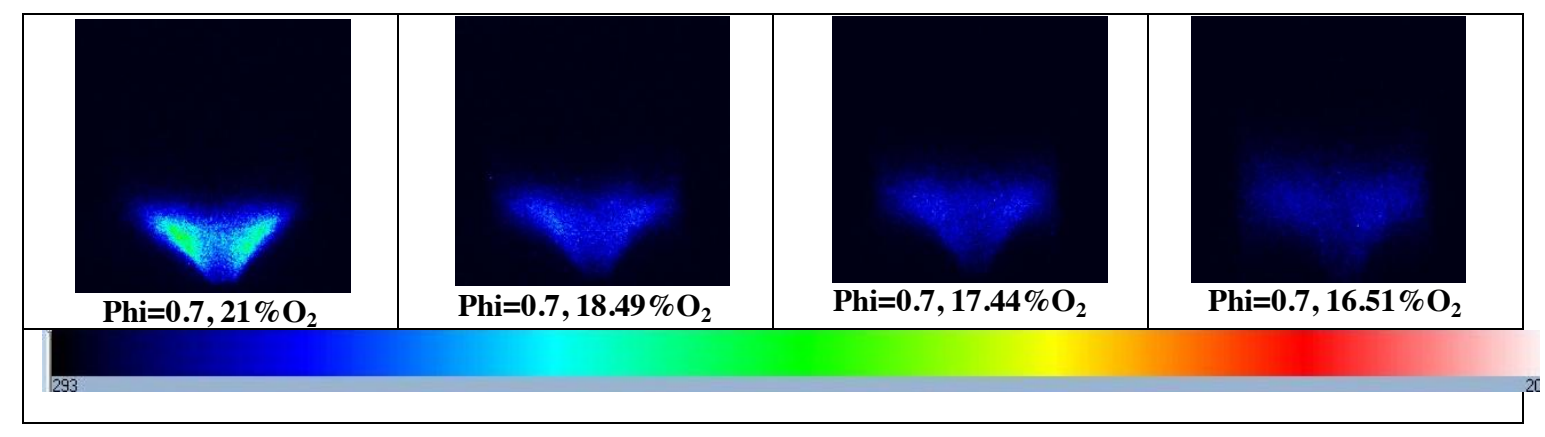

Figure 14. NO chemiluminescence signal with increased dilution (decreased oxygen concentration) at an equivalence ratio of 0.7 


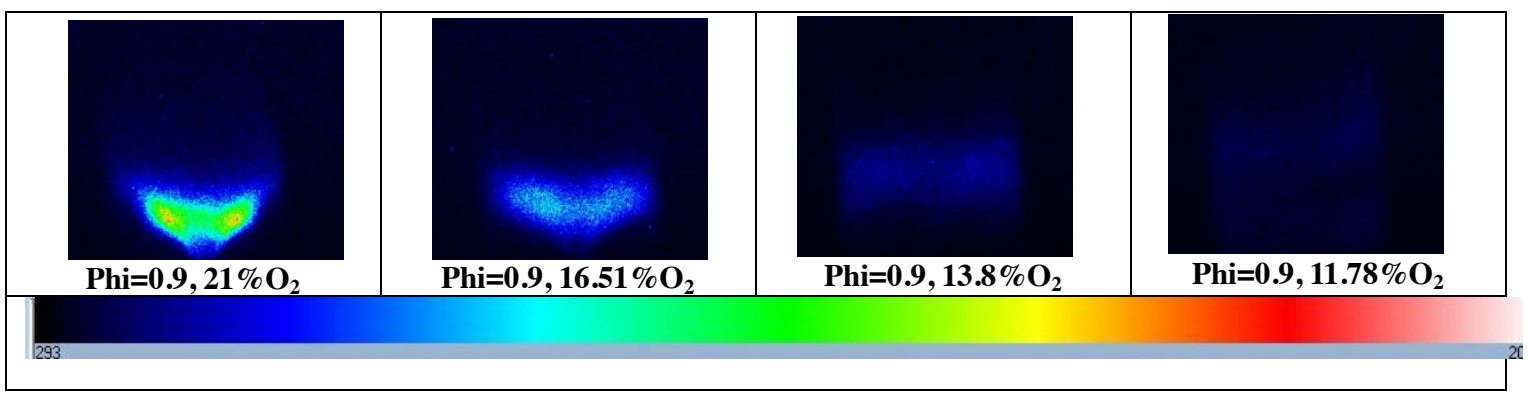

Figure 15. NO chemiluminescence signal with increased dilution (decreased oxygen concentration) at an equivalence ratio of 0.9 for diluents temperature of $600 \mathrm{~K}$ 
Table 1. Experimental parameters

\begin{tabular}{|c|c|c|c|c|}
\hline Heat Load & $\begin{array}{c}\text { Heat Release Intensity } \\
{\left[\mathbf{M W} / \mathbf{m}^{\mathbf{3}} \text {-atm] }\right.}\end{array}$ & $\begin{array}{c}\text { Mixture } \\
\text { Temperature }\end{array}$ & $\begin{array}{c}\text { Equivalence } \\
\text { Ratio }\end{array}$ & $\begin{array}{c}\text { Oxygen Concentration } \\
\text { [\%] }\end{array}$ \\
\hline $3.25 \mathrm{~kW}$ & 2.4 & $300 \mathrm{~K}$ & 0.9 & $21-13.8$ \\
\hline $3.25 \mathrm{~kW}$ & 2.4 & $300 \mathrm{~K}$ & 0.7 & $21-16.5$ \\
\hline $3.25 \mathrm{~kW}$ & 2.4 & $600 \mathrm{~K}$ & 0.9 & $21-10.7$ \\
\hline $3.25 \mathrm{~kW}$ & 2.4 & $600 \mathrm{~K}$ & 0.7 & $21-14.9$ \\
\hline
\end{tabular}

